\title{
Randomized Trial of Standard Adjuvant \\ Chemotherapy Regimens Versus Capecitabine in Older Women With Early Breast Cancer: 10-Year Update of the CALGB 49907 Trial
}

Hyman B. Muss, MD; Mei-Yin C. Polley, PhD²; Donald A. Berry, PhD ${ }^{3}$; Heshan Liu, MS²; Constance T. Cirrincione, MS ${ }^{4}$; Maria Theodoulou, MD; Ann M. Mauer, MD ${ }^{6}$; Alice B. Kornblith, PhD; Ann H. Partridge, MD, MPH ${ }^{6}$; Lynn G. Dressler, DrPH ${ }^{1}$; Harvey J. Cohen, MD ; Patricia A. Kartcheske, BS ${ }^{4}$; Edith A. Perez, MD; ${ }^{9}$ Antonio C. Wolff, MD ${ }^{10}$; Julie R. Gralow, MD ${ }^{11}$; Harold J. Burstein, MD, PhD; Ahmad A. Mahmood, MD ${ }^{8}$; Linda M. Sutton, MD ${ }^{8}$; Gustav Magrinat, MD ${ }^{12}$; Barbara A. Parker, MD ${ }^{13}$; Ronald D. Hart, MD ${ }^{14}$; Debjani Grenier, MD ${ }^{15}$; Arti Hurria, MD ${ }^{16}+$; Aminah Jatoi, MD ${ }^{17}$; Larry Norton, MD ${ }^{5}$; Clifford A. Hudis, MD Eric P. Winer, $\mathbf{M D}^{7}$; and Lisa Carey, $\mathrm{MD}^{1}$

ASSOCIATED CONTENT

Appendix

Data Supplement

Author affiliations

and support

information (if

applicable) appear

at the end of this

article.

Accepted on June 12, 2019 and published at jco.org on July 24, 2019: DOI https://doi. org/10.1200/JC0.19. 00647

The content of this article is solely the responsibility of the authors and does not necessarily represent the official views of the National Institutes of Health. Clinical trial information: NCT00024102.

\begin{abstract}
PURPOSE Older women with breast cancer remain under-represented in clinical trials. The Cancer and Leukemia Group B 49907 trial focused on women age 65 years and older. We previously reported the primary analysis after a median follow-up of 2.4 years. Standard adjuvant chemotherapy showed significant improvements in recurrence-free survival (RFS) and overall survival compared with capecitabine. We now update results at a median follow-up of 11.4 years.
\end{abstract}

PATIENTS AND METHODS Patients age 65 years or older with early breast cancer were randomly assigned to either standard adjuvant chemotherapy (physician's choice of either cyclophosphamide, methotrexate, and fluorouracil or cyclophosphamide and doxorubicin) or capecitabine. An adaptive Bayesian design was used to determine sample size and test noninferiority of capecitabine. The primary end point was RFS.

RESULTS The design stopped accrual with 633 patients at its first sample size assessment. RFS remains significantly longer for patients treated with standard chemotherapy. At 10 years, in patients treated with standard chemotherapy versus capecitabine, the RFS rates were $56 \%$ and $50 \%$, respectively (hazard ratio [HR], $0.80 ; P=.03$ ); breast cancer-specific survival rates were $88 \%$ and $82 \%$, respectively (HR, 0.62; $P=.03$ ); and overall survival rates were $62 \%$ and $56 \%$, respectively (HR, 0.84; $P=.16)$. With longer follow-up, standard chemotherapy remains superior to capecitabine among hormone receptor-negative patients (HR, 0.66; $P=$ .02), but not among hormone receptor-positive patients (HR, 0.89; $P=.43$ ). Overall, $43.9 \%$ of patients have died (13.1\% from breast cancer, $16.4 \%$ from causes other than breast cancer, and $14.1 \%$ from unknown causes). Second nonbreast cancers occurred in $14.1 \%$ of patients.

CONCLUSION With longer follow-up, RFS remains superior for standard adjuvant chemotherapy versus capecitabine, especially in patients with hormone receptor-negative disease. Competing risks in this older population dilute overall survival benefits.

\section{J Clin Oncol 37:2338-2348. @ 2019 by American Society of Clinical Oncology}

\section{INTRODUCTION}

Increasing age is the major risk factor for breast cancer. ${ }^{1}$ The average age at diagnosis of breast cancer in the United States is now 62 years, and the majority of women who die of breast cancer are age 65 years and older. ${ }^{1}$ Despite major advances over the past 30 years in prolonging breast cancer survival for women of all ages, there is some evidence that breast cancer-specific survival (BCSS) remains lowest in older women. ${ }^{2}$ The reasons for this are unclear, but most compelling is the underuse of adjuvant systemic therapy in these older patients. ${ }^{3,4}$

In 2009, the Cancer and Leukemia Group B (now part of the Alliance for Clinical Trials in Oncology) reported initial results of a randomized trial specifically designed for women with early-stage breast cancer age 65 years and older that compared standard chemotherapy (physician's choice of cyclophosphamide, methotrexate, and fluorouracil [CMF] or doxorubicin and cyclophosphamide $[\mathrm{AC}]$ ) with capecitabine. ${ }^{5}$ Previous large trials had shown that $\mathrm{CMF}$ and $\mathrm{AC}$ resulted in 


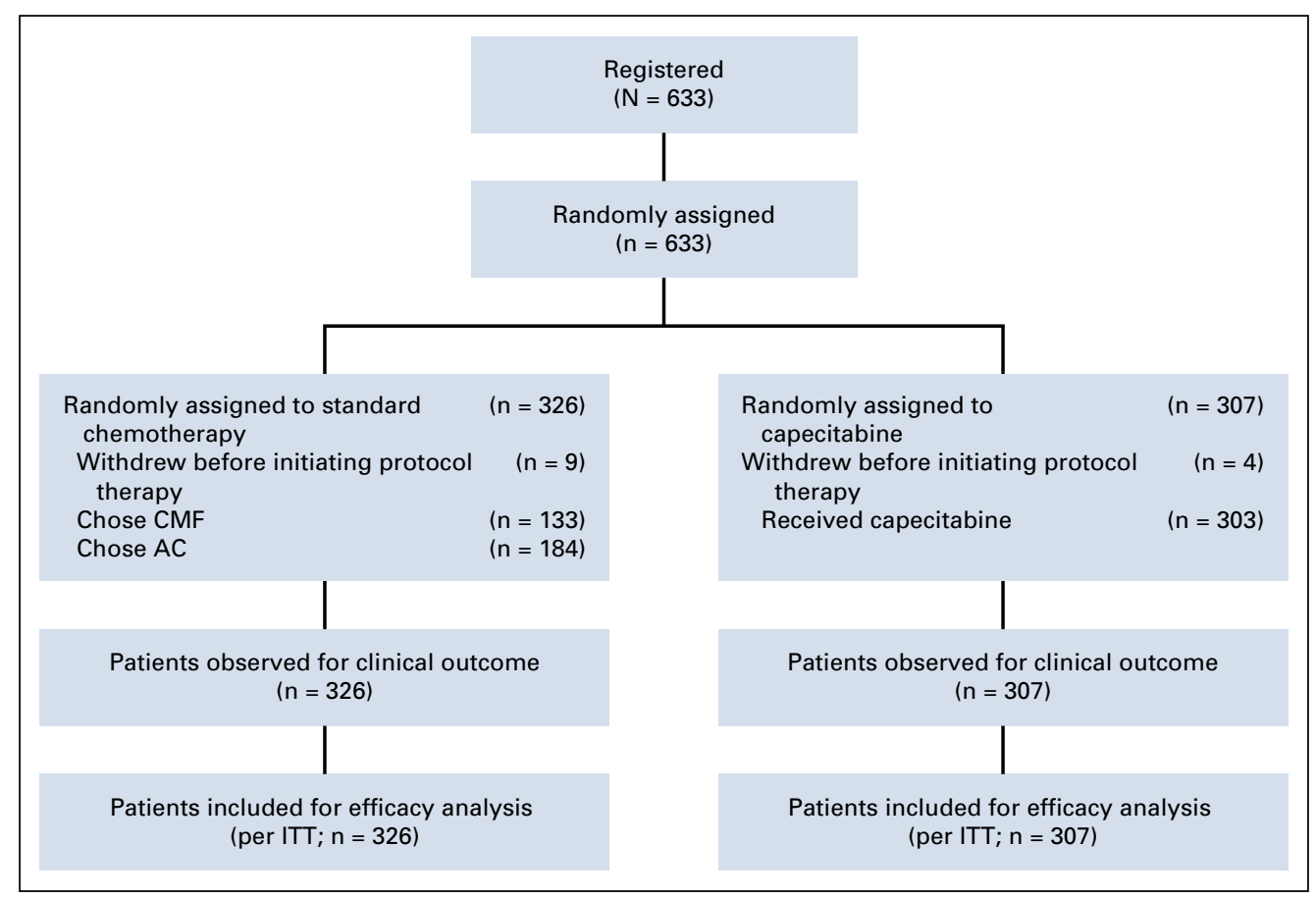

FIG 1. CONSORT diagram for Alliance/Cancer and Leukemia Group B 49907 trial. AC, doxorubicin and cyclophosphamide; CMF, cyclophosphamide, methotrexate, and fluorouracil; ITT, intent-to-treat analysis. similar outcomes in the adjuvant setting. ${ }^{6,7}$ In metastatic breast cancer, capecitabine had been shown to be associated with response rates approximating $30 \%{ }^{8}$ and, in one randomized phase $\mathrm{II}$ trial, showed similar activity to CMF. ${ }^{9}$

Our trial was designed to show recurrence-free survival (RFS) noninferiority of capecitabine and used a novel Bayesian adaptive design. After enrolling 600 patients, the probability that with longer follow-up capecitabine was highly likely to be noninferior met a prespecified cutoff value, and enrollment was discontinued. The final sample size was 633 patients. At the time of the earlier publication, the median follow-up time was 2.4 years, and the maximum follow-up time was 5.6 years. The estimated 3-year RFS rate was $85 \%$ in the standard chemotherapy group compared with $68 \%$ in the capecitabine group, and the overall survival (OS) rates were $91 \%$ and $86 \%$, respectively; both differences were statistically significant. Because of the limited follow-up in our earlier report, we now assess the risks and benefits of treatment after a median follow-up time of 11.4 years. In addition, we calculate BCSS and report on the causes of death and the frequency of second new cancers.

\section{PATIENTS AND METHODS}

\section{Patients}

Eligibility criteria required that patients be age 65 years or older with operable, histologically confirmed adenocarcinoma of the breast. Performance status had to be 0 to 2 (National Cancer Institute criteria). Patients were ineligible if they had another active malignancy with a risk of relapse of greater than $30 \%$. Complete details on eligibility criteria have been previously published ${ }^{5}$ and can also be found in the Data Supplement.

\section{Random Assignment and Study Treatment}

All patients were required to give written informed consent meeting all state, federal, and institutional guidelines. Eligible patients were randomly assigned in a one-to-one ratio to either standard chemotherapy or capecitabine. Standard chemotherapy consisted of either CMF (cyclophosphamide $100 \mathrm{mg} / \mathrm{m}^{2}$ orally on days 1 to 14 and methotrexate $40 \mathrm{mg} / \mathrm{m}^{2}$ and fluorouracil $600 \mathrm{mg} / \mathrm{m}^{2}$ on days 1 and 8 intravenously; cycles were repeated every 28 days for six cycles) or AC (doxorubicin $60 \mathrm{mg} / \mathrm{m}^{2}$ and cyclophosphamide $600 \mathrm{mg} / \mathrm{m}^{2}$ intravenously on day 1 ; cycles were repeated every 21 days for four cycles). For patients randomly assigned to standard chemotherapy, the physician and patient selected either CMF or AC. Patients randomly assigned to capecitabine received a dosage of 2,000 mg/m per day for 14 consecutive days every 3 weeks for six cycles. Doses were based on actual body weight, and there were no dose limits. For all regimens, toxicity assessment and dose modifications were based on standard National Cancer Institute Common Terminology Criteria for Adverse Events criteria (version 3.0) ${ }^{10}$ and were clearly defined in the protocol.

\section{Statistical Design}

The study was designed as a noninferiority trial comparing capecitabine with standard chemotherapy and used a unique adaptive Bayesian design. ${ }^{11}$ The primary end point was RFS, as defined by Standardized Definitions for Efficacy End Points in Adjuvant Breast Cancer Trials criteria. ${ }^{12}$ RFS events included local recurrence, distant 
TABLE 1. Baseline Patient Characteristics

No. of Patients (\%)

CMF or AC Capecitabine

\begin{tabular}{|c|c|c|}
\hline Characteristic & $(n=326)$ & $(\mathrm{n}=307)$ \\
\hline \multicolumn{3}{|l|}{ Age, years } \\
\hline $65-69$ & $110(34)$ & $108(35)$ \\
\hline 70-79 & $204(63)$ & $185(60)$ \\
\hline$\geq 80$ & $12(4)$ & $14(5)$ \\
\hline \multicolumn{3}{|l|}{ Performance status } \\
\hline $\begin{array}{l}0 \text { or } 1 \text { (fully active or } \\
\text { minimal symptoms) }\end{array}$ & 317 (97) & $295(96)$ \\
\hline $\begin{array}{c}2 \text { (symptoms, but active } \\
>50 \% \text { of the time) }\end{array}$ & $9(3)$ & $12(4)$ \\
\hline
\end{tabular}

\begin{tabular}{|c|c|c|}
\hline \multicolumn{3}{|l|}{ Race } \\
\hline White & 277 (85) & $261(85)$ \\
\hline Other & $46(14)$ & $37(12)$ \\
\hline Missing data & $3(1)$ & $9(3)$ \\
\hline \multicolumn{3}{|l|}{ Tumor size, $\mathrm{cm}$} \\
\hline$\leq 2$ & $159(49)$ & $120(39)$ \\
\hline$>2-\leq 5$ & $147(45)$ & $169(55)$ \\
\hline$>5$ & $18(6)$ & $17(6)$ \\
\hline Missing data & $2(<1)$ & $0(0)$ \\
\hline \multicolumn{3}{|l|}{ No. of positive lymph nodes } \\
\hline 0 & $90(28)$ & $95(31)$ \\
\hline $1-3$ & $180(55)$ & $157(51)$ \\
\hline $4-9$ & $39(12)$ & $42(14)$ \\
\hline$\geq 10$ & $13(4)$ & $9(3)$ \\
\hline Missing data & $4(1)$ & $4(1)$ \\
\hline \multicolumn{3}{|l|}{ Tumor grade } \\
\hline Low & $46(14)$ & $36(12)$ \\
\hline Intermediate & $124(38)$ & $132(43)$ \\
\hline High & $131(40)$ & $127(41)$ \\
\hline Missing data & $25(8)$ & $12(4)$ \\
\hline \multicolumn{3}{|l|}{ Hormone receptor status } \\
\hline Negative & $106(33)$ & $97(32)$ \\
\hline Positive & $219(67)$ & $210(68)$ \\
\hline Missing data & $1(<1)$ & $0(0)$ \\
\hline \multicolumn{3}{|l|}{ ER and PR status } \\
\hline ER negative, $\mathrm{PR}$ negative & $106(33)$ & $97(32)$ \\
\hline ER positive, PR negative & $40(12)$ & $54(18)$ \\
\hline ER negative, PR positive & $6(2)$ & $5(2)$ \\
\hline ER positive, PR positive & $172(53)$ & $150(49)$ \\
\hline Missing data & $2(1)$ & $1(<1)$ \\
\hline \multicolumn{3}{|l|}{ HER2 status } \\
\hline Positive & $39(12)$ & $37(12)$ \\
\hline Negative & $275(84)$ & $254(83)$ \\
\hline Unknown & $12(4)$ & $16(5)$ \\
\hline (continue & column) & \\
\hline
\end{tabular}

TABLE 1. Baseline Patient Characteristics (continued)

No. of Patients (\%)

CMF or AC Capecitabine

Characteristic

$(n=326) \quad(n=307)$

ER, PR, and HER2 status

ER or PR positive, HER2 negative

ER, PR, and HER2 negative (triple-negative)

\begin{tabular}{lcc}
\hline Type of surgery & $152(47)$ & $136(44)$ \\
\hline $\begin{array}{l}\text { Lumpectomy and breast } \\
\text { irradiation }\end{array}$ & $172(53)$ & $169(55)$ \\
\hline Mastectomy & $2(<1)$ & $2(<1)$ \\
\hline Missing data & $64(20)$ & $67(22)$ \\
\hline Axillary evaluation & $115(35)$ & $100(33)$ \\
\hline Sentinel node biopsy only & $142(44)$ & $136(44)$ \\
\hline Axillary dissection only & $4(1)$ & $3(<1)$ \\
\hline $\begin{array}{l}\text { Both sentinel node biopsy and } \\
\text { axillary dissection }\end{array}$ & $1(<1)$ & $1(<1)$ \\
\hline $\begin{array}{l}\text { Neither sentinel node biopsy nor } \\
\text { axillary dissection }\end{array}$ & & \\
\hline Missing data
\end{tabular}

Abbreviations: AC, doxorubicin and cyclophosphamide; CMF, cyclophosphamide, methotrexate, and fluorouracil; ER, estrogen receptor; HER2, human epidermal growth factor receptor 2; PR, progesterone receptor.

metastasis, or death as a result of any cause. The trial assumed a 5-year RFS of 60\% for standard chemotherapy, and capecitabine was considered to be noninferior if its 5 -year RFS was $53 \%$ or higher. The planned sample size was 600 to 1,800 patients. Interim monitoring was devised for both futility and noninferiority on the basis of Bayesian predictive probabilities assuming noninformative prior distributions. Interim analyses were scheduled to occur when $600,900,1,200$, and 1,500 patients had been enrolled; randomization was not adaptive. Further details on our selection of trial sample sizes have been previously published. ${ }^{5}$ OS was a secondary end point.

In this report, we also analyzed BCSS, defined as time from registration until death as a result of breast cancer. This end point was not prespecified in the protocol, and these analyses are exploratory because the cause of death was not completely ascertained in a large number of patients. For BCSS, deaths as a result of causes other than breast cancer or from unknown causes were censored at the time death occurred. All efficacy analyses were based on the intent-totreat principle and included all patients who were randomly assigned. The reverse Kaplan-Meier method was used to estimate the extent of clinical follow-up maturity. ${ }^{13}$ KaplanMeier curves were used to estimate RFS, OS, and BCSS. ${ }^{14}$ Cox proportional hazards models were used to compare 
treatment effects between arms, adjusting for tumor size, lymph node status, hormone receptor status, age, and race. These long-term outcome comparisons were not preplanned in the original protocol, which used a Bayesian adaptive design. The $P$ values presented here are descriptive only. All analyses were performed using SAS version 9.4 (SAS Institute, Cary, NC). Data collection and statistical analyses were conducted by the Alliance Statistics and Data Center. Data quality was ensured by review of data by the Alliance Statistics and Data Center and by the study chairperson following Alliance policies.

\section{RESULTS}

\section{Study Conduct}

This long-term outcome analysis is based on data available as of December 31, 2017. The trial opened for accrual on September 15, 2001, and was closed on December 29, 2006, after 633 patients had been entered. Six hundred patients were accrued as of November 2006, and the first planned analysis concluded that the probability that capecitabine would be noninferior to standard chemotherapy met our preplanned criteria for futility. The median follow-up time for RFS was 11.4 years $(95 \%$ Cl, 11.2 to 11.6 years).

\section{Patient Characteristics}

Three hundred twenty-six patients were randomly assigned to the standard treatment arm, and 307 patients were assigned to the capecitabine arm (Fig 1). Nine patients in the standard treatment arm never received treatment, leaving 317 patients who were treated (184 patients with AC and 133 patients with CMF). Patient characteristics are listed in Table 1. Approximately two thirds of the patients were age 70 years and older, and approximately 5\% were age 80 years and older. Almost all patients had excellent performance status (ambulatory and without any symptoms), and the majority of patients were white (85\%). More than half of patients had tumors larger than $2 \mathrm{~cm}$, and more than two thirds of patients had positive lymph nodes. Two thirds of patients were hormone receptor positive, and approximately $12 \%$ were human epidermal growth factor receptor 2 positive.

\section{RFS, OS, and BCSS}

For the entire cohort, the 10-year RFS, OS, and BCSS rates were $52.7 \%(95 \% \mathrm{Cl}, 48.8 \%$ to $57 \%), 59.2 \%(95 \% \mathrm{Cl}$, $55.3 \%$ to $63.4 \%$ ), and $85.4 \%(95 \% \mathrm{Cl}, 82.4 \%$ to $88.5 \%$ ), respectively (Appendix Table $\mathrm{A} 1$ and Appendix Figs $\mathrm{A} 1$ to A3, online only). Table 2 compares RFS events and OS events between our initial report and this update. Approximately half of all patients now have an RFS event, and approximately 44\% have died. Estimated 10-year RFS rates are $55.7 \%(95 \% \mathrm{Cl}, 50.2 \%$ to 61.7$)$ and $49.7 \%(95 \% \mathrm{Cl}$, $44.1 \%$ to $56 \%$ ) for standard chemotherapy and capecitabine, respectively (Fig 2). The Kaplan-Meier curves for RFS and OS seem to cross toward the later period of follow-up (Fig 2; $P=.05$ and $P=.02$ for the test of nonproportionality for RFS and OS, respectively). The nonproportionality for end points that involve non-breast cancer-specific death is not surprising given other competing causes of death in this elderly population. In the

TABLE 2. Recurrence-Free and Overall Survival Events

No. of Patients (\%)

\begin{tabular}{|c|c|c|c|c|}
\hline \multirow[b]{2}{*}{ Event or Patient Status } & \multicolumn{2}{|c|}{$2009 *$} & \multicolumn{2}{|c|}{2018} \\
\hline & CMF or AC $(n=326)$ & Capecitabine $(n=307)$ & CMF or AC $(n=326)$ & Capecitabine $(n=307)$ \\
\hline \multicolumn{5}{|l|}{ Recurrence-free survival } \\
\hline Alive without relapse & $291(89.3)$ & $247(80.5)$ & $171(52)$ & $146(48)$ \\
\hline Total events & $35(10.7)$ & $60(19.5)$ & $155(48)$ & $161(52)$ \\
\hline Local recurrence only & $5(1.5)$ & $19(6.2)$ & $17(5)$ & $28(9)$ \\
\hline Distant metastases & $15(4.6)$ & $24(7.8)$ & $41(13)$ & $44(14)$ \\
\hline Died without relapse & $15(4.6)$ & $17(5.5)$ & $97(30)$ & $89(29)$ \\
\hline \multicolumn{5}{|l|}{ Overall survival } \\
\hline Alive & $302(93)$ & $269(88)$ & $187(57)$ & $168(55)$ \\
\hline Total deaths & $24(7.4)$ & $38(12.4)$ & $139(43)$ & $139(45)$ \\
\hline \multicolumn{5}{|l|}{ Cause of death } \\
\hline Breast cancer & $8(2.5)$ & $18(5.9)$ & $34(10)$ & $49(16)$ \\
\hline Breast cancer treatment & $0(0)$ & $2(0.7)$ & 0 & $2(0.7)$ \\
\hline Cause other than breast cancer & $12(3.3)$ & $14(4.6)$ & $56(17)$ & $48(16)$ \\
\hline Unknown & $4(0.8)$ & $4(1.3)$ & 49 (15) & 40 (13) \\
\hline
\end{tabular}

Abbreviations: AC, doxorubicin and cyclophosphamide; CMF, cyclophosphamide, methotrexate, and fluorouracil.

*Data from initial publication. ${ }^{5}$ 


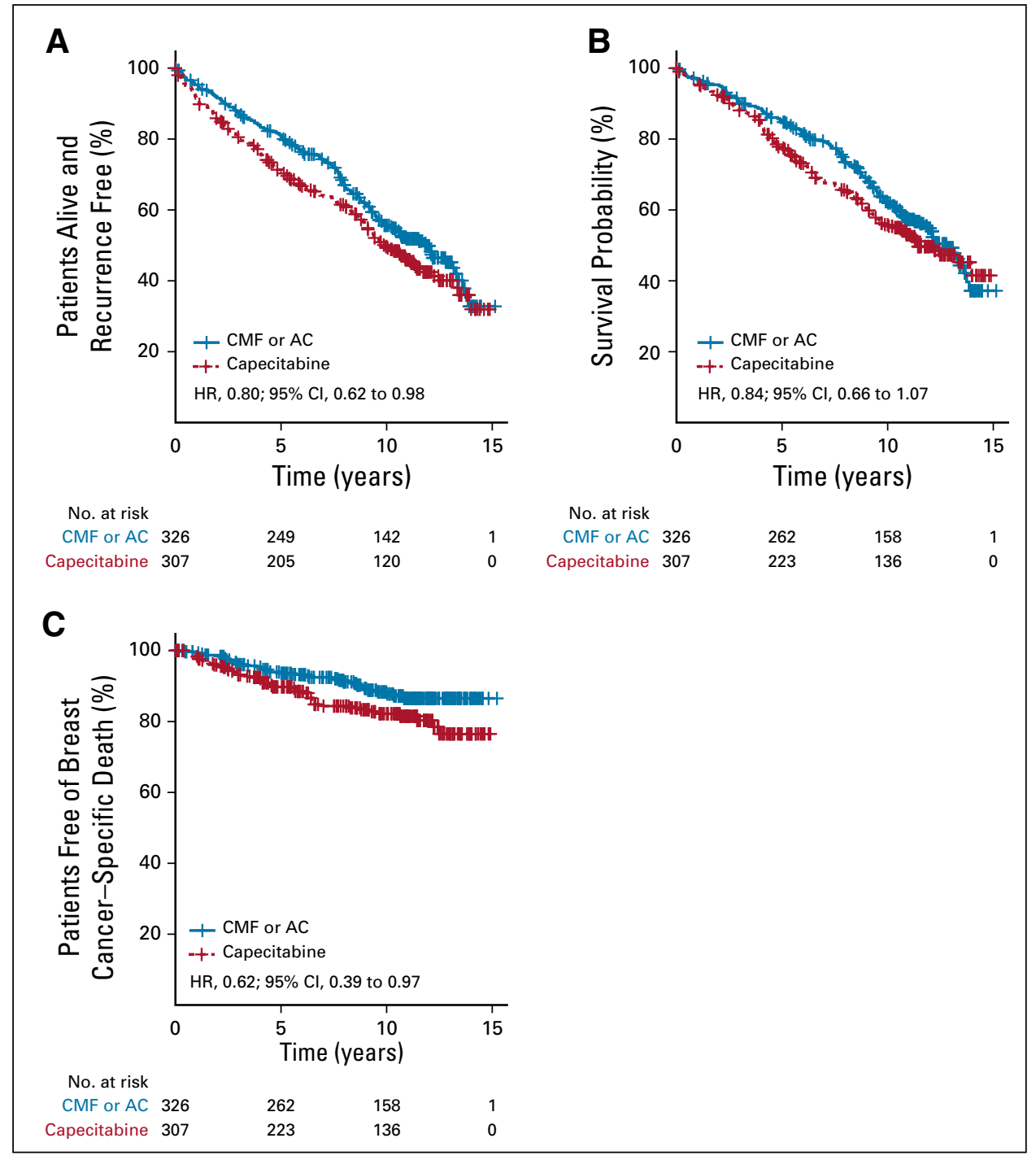

FIG 2. Kaplan-Meier plots for (A) recurrence-free survival, (B) overall survival, and (C) breast cancer-specific survival by treatment arm. AC, doxorubicin and cyclophosphamide; CMF, cyclophosphamide, methotrexate, and fluorouracil; HR, hazard ratio.

multivariable analysis (Table 3), RFS, BCSS, and OS favored patients treated with standard therapy (RFS: hazard ratio [HR], 0.80; $95 \% \mathrm{Cl}, 0.62$ to $0.98 ; P=.03$; BCSS: HR, 0.62 ; $95 \% \mathrm{Cl}, 0.39$ to 0.97 ; $P=.03$; OS: HR, $0.84 ; 95 \% \mathrm{Cl}$, 0.66 to $1.07 ; P=.16$ ). As expected and similar to our earlier report, larger tumor size, a greater number of positive nodes, and negative hormone receptor status were associated with significantly poorer outcomes, whereas race was not. Of interest, multivariable analysis also found that patients age 70 years and older had significantly poorer prognosis compared with those age 65 to 69 years. Because death from any cause is considered an RFS event and because increasing age is associated with shorter life expectancy, these findings are not unexpected. Of note, almost two thirds of RFS events were a result of deaths without relapse and were similar in both treatment groups.

At the time of this update, $43.9 \%$ of patients have died (13.1\% from breast cancer, $16.4 \%$ from non-breast cancer causes, and $14.1 \%$ from unknown causes). Second new cancers occurred in $14.7 \%$ of patients $(16.9 \%$ of patients who received standard therapy $v 12.4 \%$ of patients who received capecitabine). Breast cancer accounted for $10 \%$ and $16 \%$ of all deaths in patients treated with standard therapy versus capecitabine, respectively $(P=.045)$, whereas deaths not attributable to breast cancer were reported for $17 \%$ and $16 \%$ of patients treated with standard therapy versus capecitabine, respectively. In approximately $14 \%$ of all patients, the cause of death was unknown. Only two deaths, both in the capecitabine arm, were definitely related to treatment.

Before the development of this trial, the potential benefits of chemotherapy for patients with hormone receptor-positive versus hormone receptor-negative tumors were not well defined. In an unplanned subset analysis done for our initial report, a statistically significant interaction between treatment and receptor status was noted for both RFS and OS, and the benefits of standard chemotherapy were confined to patients with hormone receptor-negative tumors. In this 
TABLE 3. Multivariable Analysis of Treatment Effect Adjusting for Baseline Characteristics for All ITT Patients

\begin{tabular}{|c|c|c|c|c|c|c|}
\hline \multirow[b]{2}{*}{ Variable } & \multicolumn{2}{|c|}{ Recurrence-Free Survival } & \multicolumn{2}{|c|}{ Overall Survival } & \multicolumn{2}{|c|}{ Breast Cancer-Specific Survival } \\
\hline & HR (95\% Cl) & $P$ & HR (95\% Cl) & $P$ & HR (95\% CI) & $P$ \\
\hline \multicolumn{7}{|l|}{ Treatment } \\
\hline Capecitabine & 1 (Ref) & .0312 & 1 (Ref) & .1629 & 1 (Ref) & .0348 \\
\hline $\mathrm{CMF}$ or $\mathrm{AC}$ & $0.80(0.62$ to 0.98$)$ & & 0.84 (0.66 to 1.07 ) & & 0.62 (0.39 to 0.97$)$ & \\
\hline \multicolumn{7}{|l|}{ Age group, years } \\
\hline $65-69$ & 1 (Ref) & $<.001$ & 1 (Ref) & $<.001$ & 1 (Ref) & .0359 \\
\hline$\geq 70$ & 1.57 (1.21 to 2.04$)$ & & 1.85 (1.39 to 2.48$)$ & & 1.82 (1.04 to 3.18 ) & \\
\hline \multicolumn{7}{|l|}{ Race } \\
\hline White & 1 (Ref) & .6112 & 1 (Ref) & .7344 & 1 (Ref) & .664 \\
\hline Other & 1.09 (0.79 to 1.50$)$ & & $0.94(0.66$ to 1.34$)$ & & 1.14 (0.63 to 2.08$)$ & \\
\hline \multicolumn{7}{|l|}{ Tumor size, $\mathrm{cm}$} \\
\hline$\leq 2$ & 1 (Ref) & .004 & 1 (Ref) & $<.001$ & 1 (Ref) & .0011 \\
\hline$>2$ & 1.41 (1.12 to 1.79$)$ & & 1.56 (1.21 to 2.01$)$ & & 2.39 (1.41 to 4.03$)$ & \\
\hline \multicolumn{7}{|c|}{ No. of positive lymph nodes } \\
\hline 0 & 1 (Ref) & $<.001$ & 1 (Ref) & $<.001$ & 1 (Ref) & $<.001$ \\
\hline $1-3$ & 1.76 (1.31 to 2.36$)$ & & 1.73 (1.27 to 2.38 ) & & 1.95 (1.02 to 3.72 ) & \\
\hline$\geq 4$ & 2.18 (1.54 to 3.08$)$ & & 2.35 (1.63 to 3.39 ) & & 5.02 (2.63 to 9.60 ) & \\
\hline \multicolumn{7}{|c|}{ Hormone receptor status } \\
\hline Positive & 1 (Ref) & $<.001$ & 1 (Ref) & $<.001$ & 1 (Ref) & .003 \\
\hline Negative & 1.69 (1.32 to 2.16$)$ & & 1.73 (1.33 to 2.25$)$ & & 2.02 (1.27 to 3.20$)$ & \\
\hline
\end{tabular}

NOTE. Patients with any missing covariates were excluded from the analysis.

Abbreviations: AC, doxorubicin and cyclophosphamide; CMF, cyclophosphamide, methotrexate, and fluorouracil; HR, hazard ratio; ITT, intent-to-treat; Ref, reference.

follow-up analysis, RFS remains significantly better for patients with hormone receptor-negative tumors treated with standard chemotherapy compared with capecitabine (HR, 0.66; 95\% Cl, 0.46 to 0.95; $P=.02$ ), but this benefit was not observed among patients with hormone receptor-positive tumors (HR, 0.89; $95 \% \mathrm{Cl}, 0.68$ to $1.18 ; P=$ .43; Fig 3). The interaction test between treatment and hormone receptor status for RFS yielded a nominal $P=.15$, possibly as a result of the limited statistical power available for interaction tests. ${ }^{15}$ For OS and BCSS, the treatment difference did not reach statistical significance in either hormone receptor subgroup, likely because of the limited power in these subgroup analyses. Nevertheless, there was a visual trend toward greater magnitude of efficacy with standard chemotherapy among patients with hormone receptor-negative tumors.

In this update, we specifically analyzed data from the 154 patients with triple-negative breast cancer in an exploratory analysis (Appendix Table A2 to A4 and Appendix Figs A4 to $A 6$, online only). Similar to hormone receptor-negative patients, RFS was significantly improved for patients with triple-negative breast cancer treated with standard chemotherapy (HR, 0.61; 95\% Cl, 0.39 to $0.95 ; P=.03$ ). However, no significant difference was noted between the two arms for OS (HR, $0.71 ; 95 \% \mathrm{Cl}, 0.45$ to $1.14 ; P=.15$ ) or BCSS (HR, 0.56; $95 \% \mathrm{Cl}, 0.25$ to $1.25 ; P=.16$ ).

\section{Toxicity and Second Cancers}

Toxicity data have been previously published. ${ }^{5}$ Two patients on capecitabine had drug-related deaths. With longer follow-up, 89 (14.1\%) of 633 patients have developed new second primary cancers, 55 patients $(16.9 \%)$ in the standard therapy group and 38 patients $(12.4 \%)$ in the capecitabine group ( $P=.12$; Table 4 ). At this time, death attributed to congestive heart failure (six patients) or cardiomyopathy (three patients) has been noted for seven patients treated with standard therapy (AC, $n=5$; CMF, $n=$ 2) and two patients treated with capecitabine (one patient with congestive heart failure and one with cardiomyopathy). Myelodysplasia was reported in two patients (one patient treated with capecitabine and one treated with standard therapy). Acute myelogenous leukemia was reported in one patient receiving standard therapy.

\section{DISCUSSION}

Initial results of this trial showed that standard chemotherapy with CMF or AC resulted in superior RFS compared with capecitabine in older women with early-stage breast cancer. Now with longer follow-up, standard chemotherapy 


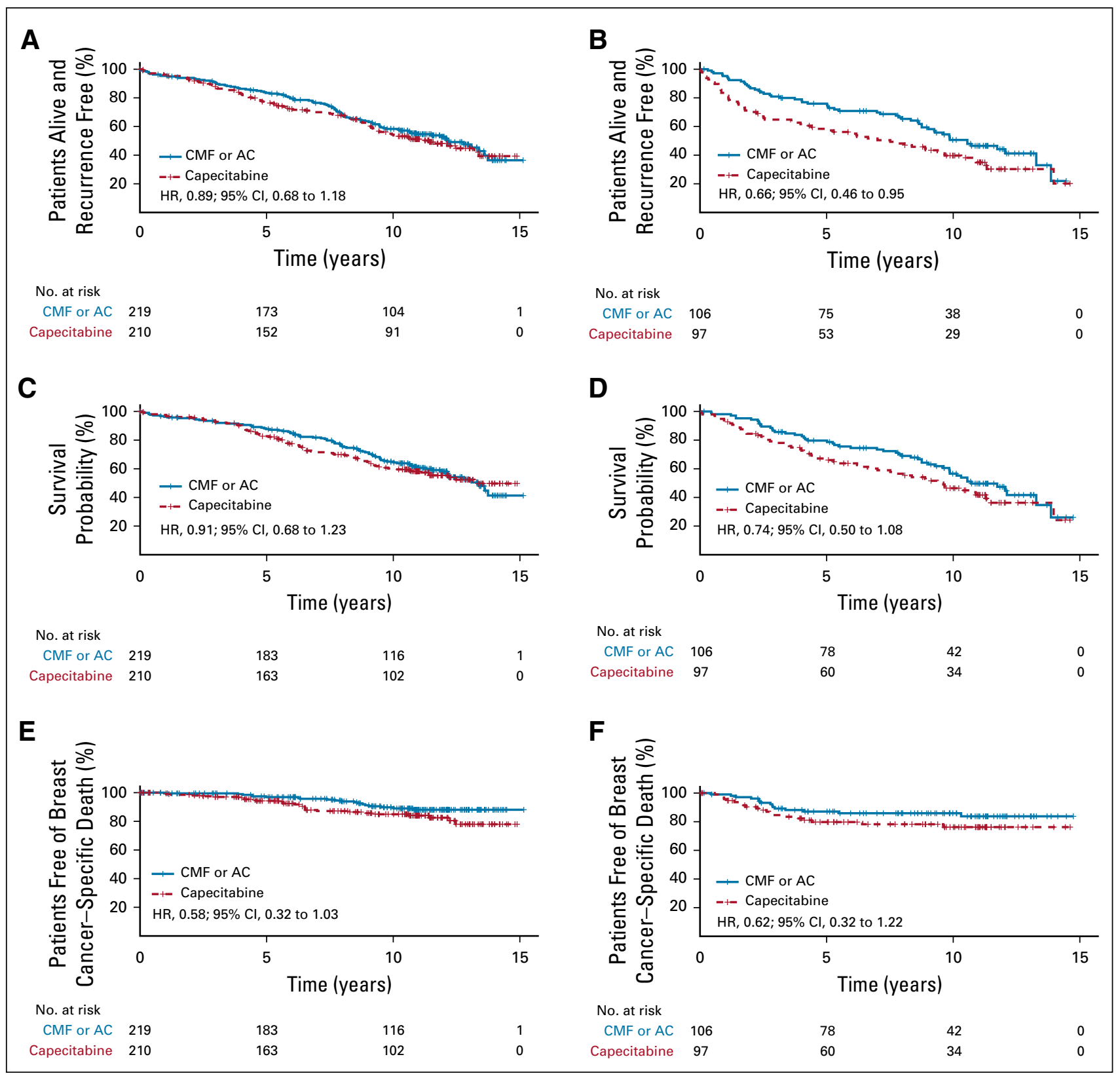

FIG 3. Kaplan-Meier plots for recurrence-free survival in patients with (A) hormone receptor-positive and (B) hormone receptor-negative tumors, overall survival in patients with (C) hormone receptor-positive and (D) hormone receptor-negative tumors, and breast cancer-specific survival in patients with (E) hormone receptor-positive and (F) hormone receptor-negative tumors by treatment arm. AC, doxorubicin and cyclophosphamide; $\mathrm{CMF}$, cyclophosphamide, methotrexate, and fluorouracil; HR, hazard ratio.

remains significantly superior to capecitabine for RFS and BCSS but not OS. Similar to our earlier report, the major benefit of standard chemotherapy was seen in RFS among patients with hormone receptor-negative disease. A difference in the rate of metastatic disease among treatment groups is no longer apparent, with most of the breast cancer relapse differences being a result of local regional recurrence. The reason for the lack of a significant survival difference after longer follow-up is likely a result of the large number of deaths from non-breast cancer causes in this older population, diluting the benefits of adjuvant treatment. ${ }^{16}$ Now with 11.4 years of follow-up, the majority of the 278 deaths in this trial were a result of causes other than breast cancer (104 deaths; $37.4 \%$ ) or unknown causes (89 deaths; $32.0 \%$ ). Only 85 of the total deaths (30.6\%) were caused by breast cancer (including two treatment-related deaths on capecitabine). Although it is uncertain how many of the deaths from unknown causes were a result of breast cancer, these data underscore the importance of competing causes of mortality in this older population. This is especially important because in this trial and most clinical 
TABLE 4. New Second Primary Cancers

No. of Patients (\%)

\begin{tabular}{lccc} 
Second Cancer & CMF or AC ( $\mathbf{n} \mathbf{5 8})$ & Capecitabine $(\mathbf{n}=\mathbf{3 8})$ & Total $(\mathbf{N}=\mathbf{9 6})$ \\
\hline Solid tumor & $24(41)$ & $14(37)$ & $38(40)$ \\
\hline Gl & $7(12)$ & $2(5)$ & $9(9)$ \\
\hline Genitourinary & $2(3)$ & $3(8)$ & $5(5)$ \\
\hline Gynecologic & $6(10)$ & $2(5)$ & $8(8)$ \\
\hline Other & $7(12)$ & $7(18)$ & $14(15)$ \\
\hline Breast & $8(14)$ & $6(16)$ & $14(15)$ \\
\hline Invasive & $5(9)$ & $3(8)$ & $8(8)$ \\
\hline DCIS/LCIS & $3(5)$ & $3(8)$ & $6(6)$ \\
\hline Skin & $6(10)$ & $6(16)$ & $12(13)$ \\
\hline Blood & $9(16)$ & $5(13)$ & $14(15)$ \\
\hline Lymphoma & $3(5)$ & $1(3)$ & $4(4)$ \\
\hline Myeloma & $1(2)$ & $2(5)$ & $2(2)$ \\
\hline Myelodysplasia & $2(3)$ & $1(3)$ & $3(3)$ \\
\hline AML & $2(3)$ & $0(0)$ & $2(2)$ \\
\hline CLL & $0(0)$ & $1(3)$ & $1(1)$ \\
\hline CML & $1(2)$ & $0(0)$ & $1(1)$ \\
\hline Unknown & $11(19)$ & $7(18)$ & $18(19)$ \\
\hline
\end{tabular}

NOTE. Among the 89 patients who developed a second cancer, there were 96 cancer occurrences in total. Six patients had multiple secondary cancer events, all on the cyclophosphamide, methotrexate, and fluorouracil (CMF) or doxorubicin and cyclophosphamide (AC) arm.

Abbreviations: AML, acute myelogenous leukemia; CLL, chronic lymphocytic leukemia; CML, chronic myelogenous leukemia; DCIS, ductal cancer in situ; LCIS, lobular cancer in situ.

trials, older patients are likely to be healthier than the older population at large.

As reported previously, toxicity was seen in the majority of patients. Only $62 \%$ of patients completed all six planned cycles of CMF, but $80 \%$ completed six planned cycles of capecitabine, and $92 \%$ completed four cycles of AC therapy. With further follow-up, death attributed to congestive heart failure or cardiomyopathy has been noted for seven patients treated with standard therapy $(A C, n=5$; $\mathrm{CMF}, \mathrm{n}=2$ ) and two treated with capecitabine. Myelodysplasia and acute myelogenous leukemia were seen in only three patients.

This trial remains among the few focused on the role of adjuvant chemotherapy in older women with breast cancer. Since the publication of our initial results in 2009, few additional randomized trials focused on this population have been performed. Two trials compared capecitabine with a nonchemotherapy control group. One randomized trial compared ibandronate with or without capecitabine in 1,358 older patients with moderate- or high-risk early breast cancer and showed no benefit for capecitabine ${ }^{17} \mathrm{~A}$ second case-control study compared 104 older patients given adjuvant capecitabine with a similar untreated control group of 147 patients. ${ }^{18}$ Considering the negative outcome from our trial and the larger trial by von Minckwitz et al, ${ }^{17}$ we do not believe that capecitabine alone has a role in the adjuvant treatment of older women with breast cancer.

Clinical trials in older patients remain sparse. A randomized trial of CMF or weekly docetaxel in 302 patients age 65 to 69 years showed no difference in outcome after a median follow-up of almost 6 years ${ }^{19}$ A second trial randomly assigned 198 nonfrail patients age 65 years and older to epirubicin and cyclophosphamide followed by CMF versus six cycles of nanoparticle albumin-bound paclitaxel and capecitabine. ${ }^{20}$ There was no difference in survival among the treatment groups at 2 years of follow-up. Two phase II trials have focused on specific regimens such as docetaxel and cyclophosphamide ${ }^{21,22}$ and liposomal doxorubicin and taxanes, but convincing outcome data were lacking ${ }^{23}$ Unfortunately, in a meta-analysis reported in 2012 of 100,000 women in 123 randomized trials, only a small percentage of patients age 70 years and older were treated, limiting our knowledge about the benefits of many newer state-of-the-art regimens in older patients. ${ }^{24}$ Accrual of older patients to groundbreaking adjuvant chemotherapy trials remains a major problem.

We have learned much about adjuvant therapy since the initial development and publication of our study. First, many of the patients enrolled in our trial would not currently be recommended to receive chemotherapy, especially many node-negative patients in whom genetic-based assays would likely suggest no benefit. ${ }^{25,26}$ In addition, although CMF and AC result in similar outcomes, ${ }^{6,7}$ the majority of lower risk patients receiving chemotherapy today are treated with docetaxel and cyclophosphamide, a combination that is superior to AC (and CMF) and that showed similar benefits for patients older and younger than 65 years. ${ }^{27}$ The use of geriatric assessment to help select older patients for chemotherapy treatment has also proven to be of great value ${ }^{28}$ because performance status misses many areas of vulnerability in older patients ${ }^{29}$ and geriatric assessment can inform the choice of interventions in addition to allowing one to accurately predict life expectancy ${ }^{30}$ and toxicity. ${ }^{31,32}$

In addition to commonly defined clinical trial outcomes including RFS, OS, BCSS, and toxicity, this trial incorporated prospectively collected ancillary data (Data Supplement) on a number of geriatric-related domains. This has resulted in numerous publications exploring the effects of the chemotherapy regimens used in our trial on quality of life, ${ }^{33}$ adherence to oral chemotherapy, ${ }^{34,35}$ selfreported cognitive function, ${ }^{36}$ lymphedema and musculoskeletal events, ${ }^{37}$ and functional decline. ${ }^{38}$ Pretreatment data were also used to assess the effects of comorbidity, ${ }^{39}$ social support, ${ }^{40}$ renal function, ${ }^{41}$ patient preferences to receive chemotherapy, ${ }^{42}$ and selected covariates $^{43}$ on patient outcomes. In addition, we developed a companion trial (ClinicalTrials.gov identifier: NCT00068328) for 
patients who declined participation in the Cancer and Leukemia Group B 49907 trial (Alliance) that ran simultaneously and that compared treatment and other outcomes with the treatment groups in our study. ${ }^{44}$ These assessments related to quality of life and function and the need for supportive care during treatment are key to discussing treatment recommendations with patients. Another unique aspect of our trial was the use of an adaptive Bayesian statistical design that allowed us to determine noninferiority with a smaller sample size while retaining the robustness of the treatment comparisons. Such adaptive designs should be considered for future trials designed specifically for older patients to facilitate accrual. The

\section{AFFILIATIONS}

${ }^{1}$ University of North Carolina Lineberger Comprehensive Cancer Center, Chapel Hill, NC

${ }^{2}$ Alliance Statistics and Data Center, Mayo Clinic, Rochester, MN

${ }^{3}$ Alliance Statistics and Data Center, The University of Texas MD

Anderson Cancer Center, Houston, TX

${ }^{4}$ Robert H Lurie Comprehensive Cancer Center, Northwestern University, Evanston, IL

${ }^{5}$ Memorial Sloan Kettering Cancer Center, New York, NY

${ }^{6}$ Advocate Illinois Masonic Medical Center, Chicago, IL

${ }^{7}$ Dana-Farber/Partners CancerCare, Boston, MA

${ }^{8}$ Duke Cancer Institute, Duke University, Durham, NC

${ }^{9}$ Mayo Clinic, Jacksonville, FL

${ }^{10}$ Sidney Kimmel Cancer Center, Johns Hopkins University,

Baltimore, MD

${ }^{11}$ University of Washington Seattle Cancer Alliance, Seattle, WA

${ }^{12}$ Cone Health Cancer Center, Greensboro, NC

${ }^{13}$ Moores Cancer Center, University of California San Diego, La Jolla, CA

${ }^{14} \mathrm{Harold}$ Alfond Center for Cancer Care, Augusta, ME

${ }^{15}$ St Boniface General Hospital, Winnipeg, Manitoba, Canada

${ }^{16}$ City of Hope Comprehensive Cancer Center, Duarte, CA

${ }^{17}$ Mayo Clinic, Rochester, MN

$\dagger$ Deceased

\section{CORRESPONDING AUTHOR}

Hyman B. Muss, MD, University of North Carolina at Chapel Hill, Campus Box 7305, 170 Manning Dr, Chapel Hill, NC 27599; e-mail: muss@ med.unc.edu.

\section{PRIOR PRESENTATION}

Presented in part at the 44th Annual Meeting of the American Society of Clinical Oncology, Chicago, May 30-June 3, 2008.

\section{SUPPORT}

Supported by the National Cancer Institute of the National Institutes of Health under Awards No. U10CA180821, U10CA180882, and UG1CA189823 (to the Alliance for Clinical Trials in Oncology); majority of patients who die of breast cancer in the United States are age 65 years and older, and our data and those of others indicate that chemotherapy can improve outcomes in this older age group. An online calculator validated in older patients can also help define the benefits of chemotherapy in patients with different tumor phenotypes. ${ }^{45}$ Optimally, we must increase the number of older patients in cancer clinical trials to have accurate data on outcomes, especially toxicity, for newer agents. Efforts are being made to overcome the age bias associated with offering older patients trial participation, ${ }^{46,47}$ but trials designed specifically for older patients and that include serial geriatric assessments are needed.

U10CA180790; U10CA180857; U10CA180867; P30CA033572; U10CA180820 and U10CA180802 (Eastern Cooperative Oncology Group-American College of Radiology Imaging Network); U10CA180888 (SWOG); and U10CA180863 (Canadian Cancer Trials Group). Also supported in part by funds from Roche.

\section{AUTHORS' DISCLOSURES OF POTENTIAL CONFLICTS OF INTEREST AND DATA AVAILABILITY STATEMENT}

Disclosures provided by the authors and data availability statement (if applicable) are available with this article at DOI https://doi.org/10.1200/ JCO.19.00647

\section{AUTHOR CONTRIBUTIONS}

Conception and design: Hyman B. Muss, Mei-Yin C. Polley, Donald A. Berry, Constance T. Cirrincione, Maria Theodoulou, Ann M. Mauer, Alice B. Kornblith, Ann H. Partridge, Lynn G. Dressler, Harvey J. Cohen, Edith A. Perez, Arti Hurria, Larry Norton, Clifford A. Hudis, Eric P. Winer Financial support: Clifford A. Hudis

Administrative support: Hyman B. Muss, Arti Hurria, Larry Norton, Clifford A. Hudis

Provision of study materials or patients: Hyman B. Muss, Ann H. Partridge, Edith A. Perez, Harold J. Burstein, Gustav Magrinat, Barbara A. Parker, Arti Hurria, Clifford A. Hudis, Lisa Carey

Collection and assembly of data: Mei-Yin C. Polley, Donald A. Berry, Heshan Liu, Constance T. Cirrincione, Maria Theodoulou, Ann H. Partridge, Lynn G. Dressler, Patricia A. Kartcheske, Antonio C. Wolff, Harold J. Burstein, Ahmad A. Mahmood, Linda M. Sutton, Gustav Magrinat, Barbara A. Parker, Ronald D. Hart, Arti Hurria, Clifford A. Hudis, Lisa Carey

Data analysis and interpretation: Hyman B. Muss, Mei-Yin C. Polley, Donald A. Berry, Heshan Liu, Constance T. Cirrincione, Alice B.

Kornblith, Ann H. Partridge, Lynn G. Dressler, Harvey J. Cohen, Edith A. Perez, Julie R. Gralow, Harold J. Burstein, Barbara A. Parker, Debjani Grenier, Arti Hurria, Aminah Jatoi, Larry Norton, Clifford A. Hudis Manuscript writing: All authors

Final approval of manuscript: All authors

Accountable for all aspects of the work: All authors

\section{REFERENCES}

1. National Cancer Institute SEER Program: Breast cancer data incidence and mortality by age. https://seer.cancer.gov/statfacts/html/breast.htm

2. Smith BD, Jiang J, McLaughlin SS, et al: Improvement in breast cancer outcomes over time: Are older women missing out? J Clin Oncol 29:4647-4653, 2011

3. Hébert-Croteau N, Brisson J, Latreille J, et al: Compliance with consensus recommendations for systemic therapy is associated with improved survival of women with node-negative breast cancer. J Clin Oncol 22:3685-3693, 2004

4. Eaker S, Dickman PW, Bergkvist L, et al: Differences in management of older women influence breast cancer survival: Results from a population-based database in Sweden. PLoS Med 3:e25, 2006 
5. Muss HB, Berry DA, Cirrincione CT, et al: Adjuvant chemotherapy in older women with early-stage breast cancer. N Engl J Med 360:2055-2065, 2009

6. Fisher B, Brown AM, Dimitrov NV, et al: Two months of doxorubicin-cyclophosphamide with and without interval reinduction therapy compared with 6 months of cyclophosphamide, methotrexate, and fluorouracil in positive-node breast cancer patients with tamoxifen-nonresponsive tumors: Results from the National Surgical Adjuvant Breast and Bowel Project B-15. J Clin Oncol 8:1483-1496, 1990

7. Fisher B, Anderson S, Tan-Chiu E, et al: Tamoxifen and chemotherapy for axillary node-negative, estrogen receptor-negative breast cancer: Findings from National Surgical Adjuvant Breast and Bowel Project B-23. J Clin Oncol 19:931-942, 2001

8. Blum JL, Jones SE, Buzdar AU, et al: Multicenter phase II study of capecitabine in paclitaxel-refractory metastatic breast cancer. J Clin Oncol 17:485-493, 1999

9. Oshaughnessy JA, Blum J, Moiseyenko V, et al: Randomized, open-label, phase II trial of oral capecitabine (Xeloda) vs. a reference arm of intravenous CMF (cyclophosphamide, methotrexate and 5-fluorouracil) as first-line therapy for advanced/metastatic breast cancer. Ann Oncol 12:1247-1254, 2001

10. National Cancer Institute: Common Terminology Criteria for Adverse Events (CTCAE). https://ctep.cancer.gov/protocolDevelopment/electronic_applications/ ctc.htm

11. Berry DA: Bayesian clinical trials. Nat Rev Drug Discov 5:27-36, 2006

12. Hudis CA, Barlow WE, Costantino JP, et al: Proposal for standardized definitions for efficacy end points in adjuvant breast cancer trials: The STEEP system. J Clin Oncol 25:2127-2132, 2007

13. Korn EL: Censoring distributions as a measure of follow-up in survival analysis. Stat Med 5:255-260, 1986

14. Kaplan EL, Meier P: Nonparametric estimation from incomplete observations. J Am Stat Assoc 53:457-481, 1958

15. Polley MY, Freidlin B, Korn EL, et al: Statistical and practical considerations for clinical evaluation of predictive biomarkers. J Natl Cancer Inst 105:1677-1683, 2013

16. Muss HB, Woolf S, Berry D, et al: Adjuvant chemotherapy in older and younger women with lymph node-positive breast cancer. JAMA 293:1073-1081, 2005

17. Von Minckwitz G, Reimer T, Potenberg J, et al: The phase III ICE study: Adjuvant ibandronate with or without capecitabine in elderly patients with moderate or high risk early breast cancer (GBG 32, BIG 4-04). Cancer Res 75, 2015 (suppl 9; abstr S3-04)

18. Li YS, Yang Q, Qi M, et al: Evaluation of the clinical benefits of adjuvant capecitabine monotherapy in elderly women with breast cancer: A retrospective study. Mol Clin Oncol 7:661-666, 2017

19. Perrone F, Nuzzo F, Di Rella F, et al: Weekly docetaxel versus CMF as adjuvant chemotherapy for older women with early breast cancer: Final results of the randomized phase III ELDA trial. Ann Oncol 26:675-682, 2015

20. von Minckwitz G, Conrad B, Reimer T, et al: A randomized phase 2 study comparing EC or CMF versus nab-paclitaxel plus capecitabine as adjuvant chemotherapy for nonfrail elderly patients with moderate to high-risk early breast cancer (ICE II-GBG 52). Cancer 121:3639-3648, 2015

21. Freyer G, Campone M, Peron J, et al: Adjuvant docetaxel/cyclophosphamide in breast cancer patients over the age of 70: Results of an observational study. Crit Rev Oncol Hematol 80:466-473, 2011

22. Brouwers B, Hatse S, Dal Lago L, et al: The impact of adjuvant chemotherapy in older breast cancer patients on clinical and biological aging parameters. Oncotarget 7:29977-29988, 2016

23. Gil-Gil MJ, Bellet M, Morales S, et al: Pegylated liposomal doxorubicin plus cyclophosphamide followed by paclitaxel as primary chemotherapy in elderly or cardiotoxicity-prone patients with high-risk breast cancer: Results of the phase II CAPRICE study. Breast Cancer Res Treat 151:597-606, 2015

24. Peto R, Davies C, Godwin J, et al: Comparisons between different polychemotherapy regimens for early breast cancer: Meta-analyses of long-term outcome among 100,000 women in 123 randomised trials. Lancet 379:432-444, 2012

25. Cardoso F, van't Veer LJ, Bogaerts J, et al: 70-gene signature as an aid to treatment decisions in early-stage breast cancer. N Engl J Med 375:717-729, 2016

26. Sparano JA, Gray RJ, Makower DF, et al: Adjuvant chemotherapy guided by a 21-gene expression assay in breast cancer. N Engl J Med 379:111-121, 2018

27. Jones S, Holmes FA, O'Shaughnessy J, et al: Docetaxel with cyclophosphamide is associated with an overall survival benefit compared with doxorubicin and cyclophosphamide: 7-year follow-up of US Oncology Research Trial 9735. J Clin Oncol 27:1177-1183, 2009

28. Parks RM, Lakshmanan R, Winterbottom L, et al: Comprehensive geriatric assessment for older women with early breast cancer: A systematic review of literature. World J Surg Oncol 10:88, 2012

29. Jolly TA, Deal AM, Nyrop KA, et al: Geriatric assessment-identified deficits in older cancer patients with normal performance status. Oncologist 20:379-385, 2015

30. Yourman LC, Lee SJ, Schonberg MA, et al: Prognostic indices for older adults: A systematic review. JAMA 307:182-192, 2012

31. Extermann M, Boler I, Reich RR, et al: Predicting the risk of chemotherapy toxicity in older patients: The Chemotherapy Risk Assessment Scale for High-Age Patients (CRASH) score. Cancer 118:3377-3386, 2012

32. Hurria A, Mohile S, Gajra A, et al: Validation of a prediction tool for chemotherapy toxicity in older adults with cancer. J Clin Oncol 34:2366-2371, 2016

33. Kornblith $A B$, Lan L, Archer L, et al: Quality of life of older patients with early-stage breast cancer receiving adjuvant chemotherapy: A companion study to Cancer and Leukemia Group B 49907. J Clin Oncol 29:1022-1028, 2011

34. Partridge $\mathrm{AH}$, Archer $\mathrm{L}$, Kornblith $\mathrm{AB}$, et al: Adherence and persistence with oral adjuvant chemotherapy in older women with early-stage breast cancer in CALGB 49907: Adherence companion study 60104. J Clin Oncol 28:2418-2422, 2010

35. Wang XS, Zhao F, Fisch MJ, et al: Prevalence and characteristics of moderate to severe fatigue: A multicenter study in cancer patients and survivors. Cancer 120:425-432, 2014

36. Freedman RA, Pitcher B, Keating NL, et al: Cognitive function in older women with breast cancer treated with standard chemotherapy and capecitabine on Cancer and Leukemia Group B 49907. Breast Cancer Res Treat 139:607-616, 2013

37. Hopkins JO, Allred J, Hurria A, et al: Lymphedema, musculoskeletal events and arm function in older patients receiving adjuvant chemotherapy for breast cancer (Alliance A171302). Breast Cancer Res Treat 166:793-808, 2017

38. Hurria A, Soto-Perez-de-Celis E, Allred JB, et al: Functional decline and resilience in older women receiving adjuvant chemotherapy for breast cancer. J Am Geriatr Soc 67:920-927, 2019

39. Klepin HD, Pitcher BN, Ballman KV, et al: Comorbidity, chemotherapy toxicity, and outcomes among older women receiving adjuvant chemotherapy for breast cancer on a clinical trial: CALGB 49907 and CALGB 361004 (Alliance). J Oncol Pract 10:e285-e292, 2014

40. Jatoi A, Muss H, Allred JB, et al: Social support and its implications in older, early-stage breast cancer patients in CALGB 49907 (Alliance A171301). Psychooncology 25:441-446, 2016

41. Lichtman SM, Cirrincione CT, Hurria A, et al: Effect of pretreatment renal function on treatment and clinical outcomes in the adjuvant treatment of older women with breast cancer: Alliance A171201, an ancillary study of CALGB/CTSU 49907. J Clin Oncol 34:699-705, 2016

42. Gajra A, McCall L, Muss HB, et al: The preference to receive chemotherapy and cancer-related outcomes in older adults with breast cancer CALGB 49907 (Alliance). J Geriatr Oncol 9:221-227, 2018 
43. Kimmick GG, Major B, Clapp J, et al: Using ePrognosis to estimate 2-year all-cause mortality in older women with breast cancer: Cancer and Leukemia Group B (CALGB) 49907 and 369901 (Alliance A151503). Breast Cancer Res Treat 163:391-398, 2017

44. Mandelblatt JS, Makgoeng SB, Luta G, et al: A planned, prospective comparison of short-term quality of life outcomes among older patients with breast cancer treated with standard chemotherapy in a randomized clinical trial vs. an observational study: CALGB \#49907 and \#369901. J Geriatr Oncol 4:353-361, 2013

45. de Glas NA, Bastiaannet E, Engels CC, et al: Validity of the online PREDICT tool in older patients with breast cancer: A population-based study. Br J Cancer 114 : 395-400, 2016

46. Hurria A, Dale W, Mooney M, et al: Designing therapeutic clinical trials for older and frail adults with cancer: U13 conference recommendations. J Clin Oncol 32: 2587-2594, 2014

47. Hurria A, Levit LA, Dale W, et al: Improving the evidence base for treating older adults with cancer: American Society of Clinical Oncology statement. J Clin Oncol 33:3826-3833, 2015

\section{Multidisciplinary Molecular Tumor Boards New in 2019 - FREE to All}

These free, case-based activities include a patient presentation, discussion with your colleagues, and takeaways and viewpoints from a medical oncologist and pathologist. Upcoming cancer cases include pancreatic, gastric MMR, lung MET, lymphoma, laryngeal, bladder, cervical, AML, genitourinary, NSCLC, breast PTEN, and more.

Claim 1.5 CME/CE/CNE/CPE Credits and ABIM MOC Points upon completion of each MMTB activity.

\section{ASCO University}


Randomized Trial of Standard Adjuvant Chemotherapy Regimens Versus Capecitabine in Older Women With Early Breast Cancer: 10-Year Update of the CALGB 49907 Trial

The following represents disclosure information provided by authors of this manuscript. All relationships are considered compensated. Relationships are self-held unless noted. I = Immediate Family Member, Inst = My Institution. Relationships may not relate to the subject matter of this manuscript. For more information about ASCO's conflict of interest policy, please refer to www.asco.org/rwc or ascopubs.org/jco/site/ifc.

Donald A. Berry

Employment: Berry Consultants

Leadership: Berry Consultants

Stock and Other Ownership Interests: Berry Consultants

Consulting or Advisory Role: Berry Consultants

Research Funding: Daiichi Sankyo

Travel, Accommodations, Expenses: Berry Consultants

Maria Theodoulou

Honoraria: Genentech, Pfizer, Puma Biotechnology

Consulting or Advisory Role: Genentech, Puma Biotechnology

Speakers' Bureau: Genentech, Puma Biotechnology, Pfizer

Travel, Accommodations, Expenses: Pfizer, Genentech, Puma Biotechnology

Ann H. Partridge

Patents, Royalties, Other Intellectual Property: I receive small royalty payments for co-authoring the breast cancer survivorship section of UpToDate

\section{Edith A. Perez}

Employment: Genentech

Stock and Other Ownership Interests: Genentech

Consulting or Advisory Role: Seattle Genetics, Puma Biotechnology, Daiichi Sankyo

Antonio C. Wolff

Research Funding: Myriad Genetics (Inst), Pfizer (Inst), Biomarin (Inst), Celldex (Inst)

Patents, Royalties, Other Intellectual Property: Antonio C. Wolff has been named as inventor on one or more issued patents or pending patent applications relating to methylation in breast cancer and has assigned his rights to Johns Hopkins University (JHU) and participates in a royalty-sharing agreement with JHU

Julie R. Gralow

Consulting or Advisory Role: Novartis, Genentech, Pfizer, Merck, Puma Biotechnology, Sandoz, AstraZeneca, Immunomedics, Genomic Health

Linda M. Sutton

Employment: Proteus Digital Health

Consulting or Advisory Role: Proteus Digital Health

Research Funding: Pfizer, AstraZeneca, Astellas Pharma

Barbara A. Parker

Stock and Other Ownership Interests: Merck (I)

Honoraria: EMD Serono (I)

Consulting or Advisory Role: BioAtla (I)

Research Funding: GlaxoSmithKline (Inst), Genentech (Inst), Novartis, Pfizer Oncternal Therapeutics

Patents, Royalties, Other Intellectual Property: Licensing fees for technique involving protein-interaction technology (I)

Travel, Accommodations, Expenses: EMD Serono (I)
Debjani Grenier

Consulting or Advisory Role: Merck, Puma

Arti Hurria

Consulting or Advisory Role: Boehringer Ingelheim, Sanofi, Pierian Biosciences, MJH Healthcare Holdings

Research Funding: GlaxoSmithKline, Celgene, Novartis

Larry Norton

Honoraria: BluPrint Oncology Concepts, $\mathrm{MCl}$ Breast Cancer Symposium, Advanced Breast Cancer 4 International Consensus Conference, Context Therapeutics, Celgene, Cancer MoonShot Initiative, Sermonix Oncology Ad Board, Prime Oncology, Sarah Lawrence Lecture, Context Advisory Board, Oncology Pioneers Science Lecture Series, BCRP Programmatic Review Meeting

Consulting or Advisory Role: BluPrint Oncology Concepts, $\mathrm{MCl}$ Breast Cancer Symposium, Advanced Breast Cancer International Consensus Conference, Context Therapeutics, Cancer MoonShot Initiative, Sermonix Oncology Ad Board, Prime Oncology, Sarah Lawrence Lecture, Context Advisory Board, Oncology Grand Rounds at Hackensack University Medical Center, Oncology Pioneers Science Lecture, Martell Diagnostics, BCRP Programmatic Review Meeting

Travel, Accommodations, Expenses: Celgene, Advanced Breast Cancer International Consensus Conference, $\mathrm{MCl}$ Breast Cancer Symposium, Pfizer, UCSF Breast Oncology Program 2018 Scientific Retreat, BIG Scientific Meeting, Samus Therapeutics, Oncology Pioneers Science Lecture Series, BCRP Programmatic Review Meeting

\section{Eric P. Winer}

Stock and Other Ownership Interests: Verastem

Honoraria: Genentech, Tesaro, Eli Lilly, Carrick Therapeutics, GlaxoSmithKline, Jounce Therapeutics, Genomic Health, Seattle Genetics, Merck

Consulting or Advisory Role: Leap Therapeutics, Seattle Genetics Research Funding: Genentech (Inst)

Lisa Carey

Research Funding: Innocrin Pharma (Inst), Syndax (Inst), Immunomedics (Inst) Patents, Royalties, Other Intellectual Property: Royalty-sharing agreement, investorship interest in licensed IP to startup company, Falcon Therapeutics, that is designing neural stem-cell-based therapy for glioblastoma multiforme (I)

No other potential conflicts of interest were reported. 


\section{APPENDIX}

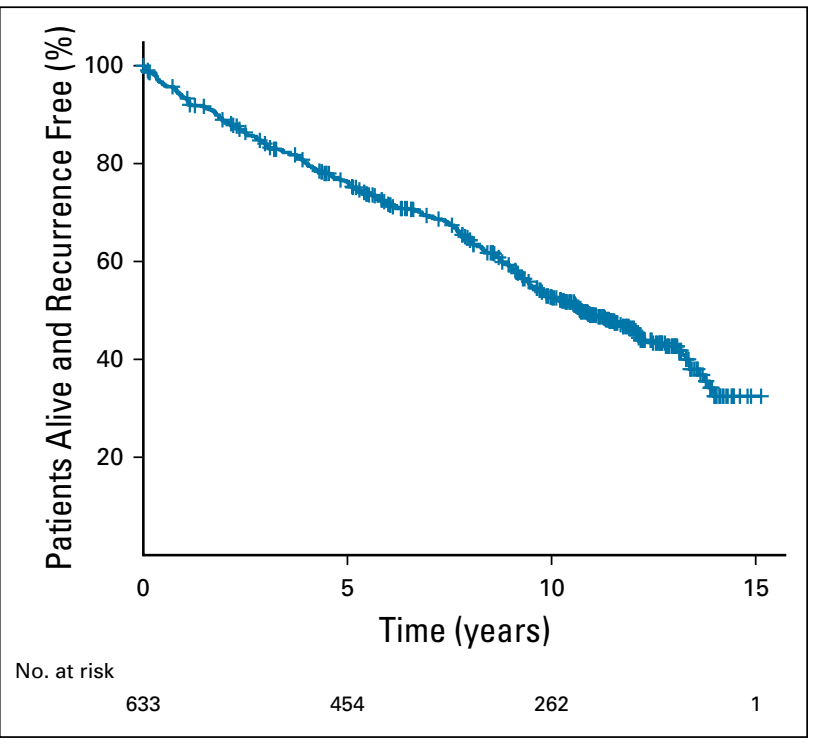

FIG A1. Relapse-free survival for all patients.

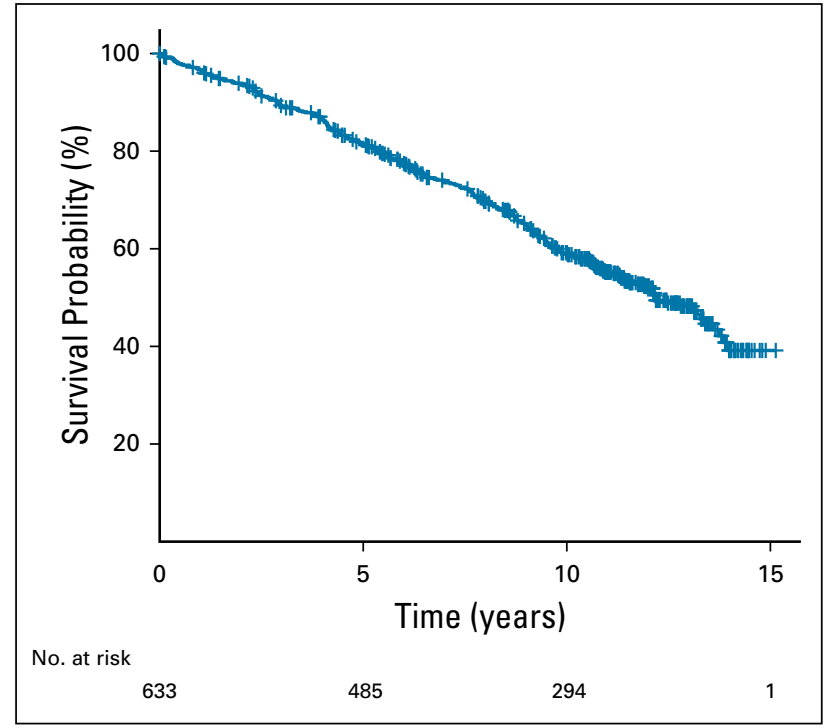

FIG A2. Overall survival for all patients. 


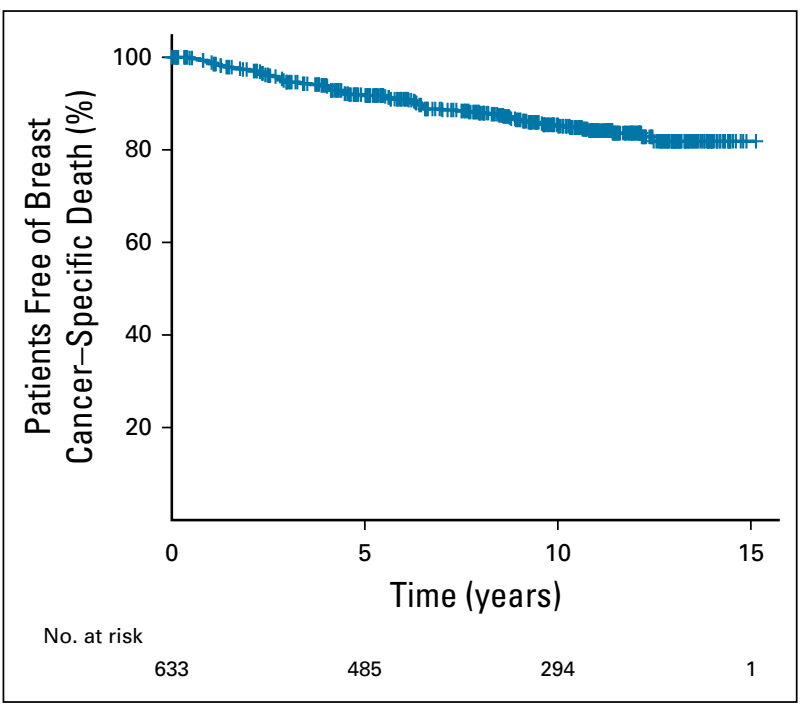

FIG A3. Breast cancer-specific survival for all patients.

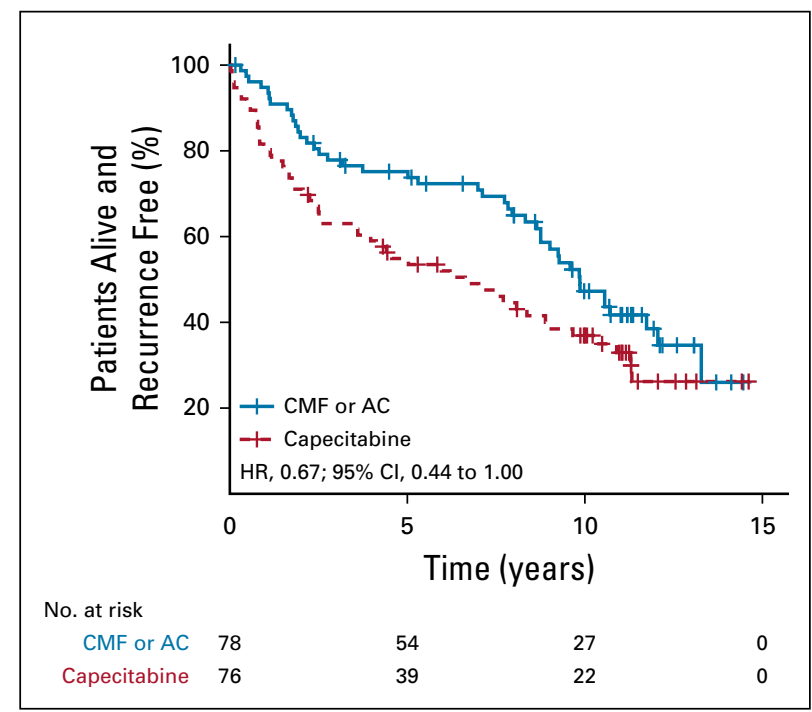

FIG A4. Kaplan-Meier plots for recurrence-free survival in patients with triple-negative breast cancer. AC, doxorubicin and cyclophosphamide; CMF, cyclophosphamide, methotrexate, and fluorouracil; $\mathrm{HR}$, hazard ratio. 


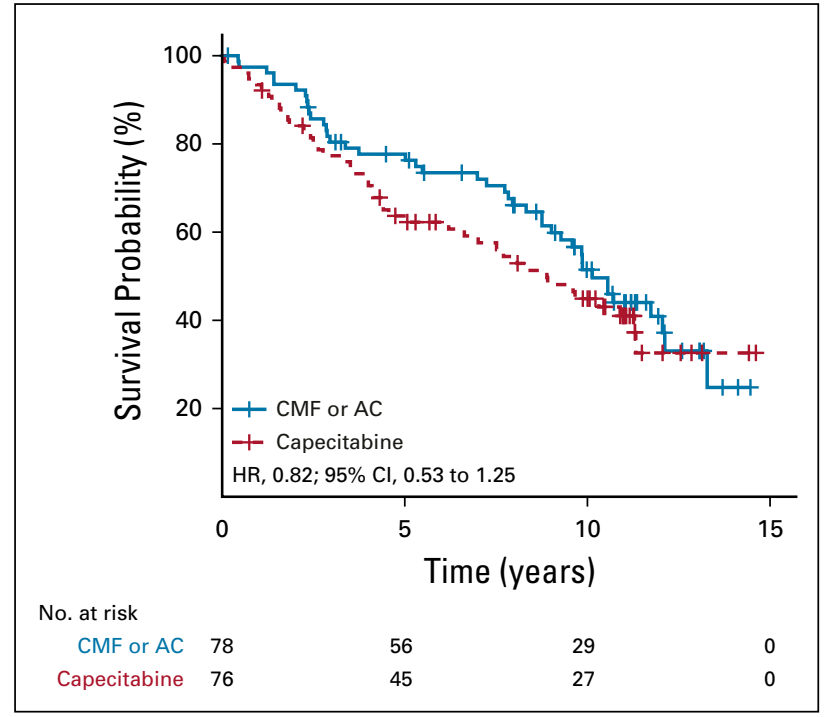

FIG A5. Kaplan-Meier plots for overall survival in patients with triplenegative breast cancer. AC, doxorubicin and cyclophosphamide; CMF, cyclophosphamide, methotrexate, and fluorouracil; HR, hazard ratio.

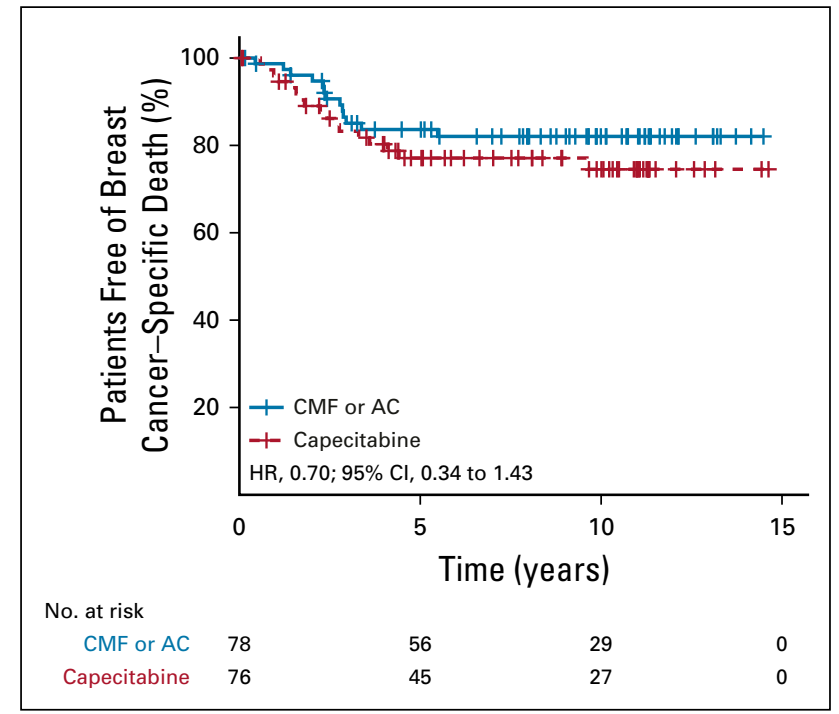

FIG A6. Kaplan-Meier plots for breast cancer-specific survival in patients with triple-negative breast cancer. AC, doxorubicin and cyclophosphamide; CMF, cyclophosphamide, methotrexate, and fluorouracil; HR, hazard ratio. 
TABLE A1. RFS, OS, and BCSS Estimates at 5 and 10 Years

10-Year Estimate (\%; 95\% Cl)

\begin{tabular}{lccc}
\hline RFS & $10.7(9.7$ to 12.1$)$ & $76.3(73.0$ to 79.7$)$ & 52.7 (48.8 to 57.0$)$ \\
\hline OS & $12.2(11.3$ to 13.6$)$ & $81.6(78.6$ to 84.7$)$ & $59.2(55.3$ to 63.4$)$ \\
\hline BCSS & NA & $91.7(89.5$ to 94.0) & 85.4 (82.4 to 88.5)
\end{tabular}

NOTE. Median follow-up times were 11.4 years (95\% Cl, 11.2 to 11.6 years) for relapse-free survival (RFS), 11.4 years (95\% Cl, 11.3 to 11.7 years) for overall survival (OS), and 10.5 years ( $95 \% \mathrm{Cl}, 10.0$ to 10.8 years) for breast cancer-specific survival (BCSS).

Abbreviations: NA, not available; ITT, intent to treat.

TABLE A2. Characteristics of Patients With Triple-Negative Breast Cancer

No. of Patients (\%)

\begin{tabular}{|c|c|c|c|}
\hline \multirow[b]{2}{*}{ Characteristic } & \multicolumn{2}{|c|}{ No. of Patients (\%) } & \multirow[b]{2}{*}{$\begin{array}{l}P \text { (Fisher's } \\
\text { exact test) }\end{array}$} \\
\hline & $\begin{array}{c}\text { CMF or AC } \\
(n=78)\end{array}$ & $\begin{array}{l}\text { Capecitabine } \\
\quad(n=76)\end{array}$ & \\
\hline Age group, years & & & .10 \\
\hline $65-69$ & $14(18)$ & $25(33)$ & \\
\hline 70-79 & $57(73)$ & $45(59)$ & \\
\hline$\geq 80$ & $7(9)$ & $6(8)$ & \\
\hline Performance score & & & 1.00 \\
\hline $\begin{array}{l}0 \text { or } 1 \text { (fully active or minimal } \\
\text { symptoms) }\end{array}$ & $75(96)$ & $73(96)$ & \\
\hline $\begin{array}{c}2 \text { (symptoms, but active } \\
>50 \% \text { of the time) }\end{array}$ & $9(4)$ & $3(4)$ & \\
\hline Race or ethnic group & & & .65 \\
\hline White & $67(86)$ & $62(82)$ & \\
\hline Other race & $10(1)$ & $12(3)$ & \\
\hline Missing data & $1(13)$ & $2(16)$ & \\
\hline Tumor size, $\mathrm{cm}$ & & & .24 \\
\hline$\leq 2$ & $39(49)$ & 30 (39) & \\
\hline$>2$ to $\leq 5$ & $36(45)$ & $45(55)$ & \\
\hline$>5$ & $3(6)$ & $1(6)$ & \\
\hline \multicolumn{4}{|l|}{ No. of positive lymph nodes } \\
\hline 0 & $37(47)$ & $36(47)$ & .55 \\
\hline $1-3$ & $30(38)$ & $25(33)$ & \\
\hline $4-9$ & $8(10)$ & $12(16)$ & \\
\hline$\geq 10$ & $1(1)$ & $0(0)$ & \\
\hline Missing data & $2(3)$ & $3(1)$ & \\
\hline Tumor grade & & & .28 \\
\hline Low & $3(4)$ & $0(0)$ & \\
\hline Intermediate & $17(22)$ & $19(25)$ & \\
\hline High & $49(63)$ & $54(71)$ & \\
\hline Missing data & $9(12)$ & $3(4)$ & \\
\hline Type of surgery & & & .42 \\
\hline $\begin{array}{l}\text { Lumpectomy and breast } \\
\text { irradiation }\end{array}$ & $36(47)$ & $41(54)$ & \\
\hline Mastectomy & $42(53)$ & $35(46)$ & \\
\hline (continu & on followi & page) & \\
\hline
\end{tabular}


TABLE A2. Characteristics of Patients With Triple-Negative Breast Cancer (continued)

\begin{tabular}{llll} 
& \multicolumn{2}{c}{ No. of Patients (\%) } & \\
\cline { 2 - 3 } Characteristic & $\begin{array}{c}\text { CMF or AC } \\
(\mathbf{n}=\mathbf{7 8})\end{array}$ & $\begin{array}{c}\text { Capecitabine } \\
(\mathbf{n}=\mathbf{7 6})\end{array}$ & $\begin{array}{c}\boldsymbol{P} \text { (Fisher's } \\
\text { exact test) }\end{array}$ \\
\hline Axillary evaluation & & & .93 \\
\hline Sentinel node biopsy only & $22(28)$ & $23(30)$ & \\
\hline Axillary dissection only & $29(37)$ & $25(33)$ \\
\hline $\begin{array}{c}\text { Both sentinel node biopsy and } \\
\text { axillary dissection }\end{array}$ & $26(33)$ & $27(36)$ \\
\hline $\begin{array}{c}\text { Neither sentinel node biopsy } \\
\text { nor axillary dissection }\end{array}$ & $1(1)$ & $1(<1)$ \\
\end{tabular}

Abbreviations: AC, doxorubicin and cyclophosphamide; CMF, cyclophosphamide, methotrexate, and fluorouracil.

TABLE A3. Kaplan-Meier Estimates for Patients with Triple-Negative Breast Cancer

\begin{tabular}{lcll}
\hline RFS & $8.9(7.7$ to 10.6$)$ & $65.1(63.7$ to 78.4$)$ & $42.2(34.7$ to 51.3$)$ \\
\hline OS & $9.8(8.8$ to 11.3$)$ & $70.7(78.6$ to 84.7$)$ & $48.2(40.5$ to 57.4$)$ \\
\hline BCSS & NA & $80.4(74.2$ to 87.2$)$ & $78.4(71.7$ to 85.7$)$
\end{tabular}

Abbreviations: BCSS, breast cancer-specific survival; NA, not available; OS, overall survival; RFS, relapse-free survival. 
TABLE A4. Multivariable Cox Proportional Hazards Models for Patients With Triple-Negative Breast Cancer $(\mathrm{N}=154)$

Relapse-Free Survival

\begin{tabular}{|c|c|c|c|c|c|c|}
\hline \multirow[b]{2}{*}{ Variable } & \multicolumn{2}{|c|}{ Relapse-Free Survival } & \multicolumn{2}{|c|}{ Overall Survival } & \multicolumn{2}{|c|}{ Breast Cancer-Specific Survival } \\
\hline & HR (95\% CI) & $P$ & HR $(95 \% \mathrm{CI})$ & $P$ & HR $(95 \% \mathrm{CI})$ & $P$ \\
\hline \multicolumn{7}{|l|}{ Treatment } \\
\hline Capecitabine & 1 (Ref) & .0296 & 1 (Ref) & .1533 & 1 (Ref) & .1564 \\
\hline $\mathrm{CMF}$ or $\mathrm{AC}$ & 0.61 (0.39 to 0.95$)$ & & $0.71(0.45$ to 1.14$)$ & & 0.56 (0.25 to 1.25$)$ & \\
\hline \multicolumn{7}{|l|}{ Age group, years } \\
\hline $65-69$ & 1 (Ref) & .1693 & 1 (Ref) & .0654 & 1 (Ref) & .1338 \\
\hline$\geq 70$ & 1.49 (0.84 to 2.63$)$ & & 1.84 (0.96 to 3.54$)$ & & $3.18(0.70$ to 14.41$)$ & \\
\hline \multicolumn{7}{|l|}{ Race } \\
\hline White & 1 (Ref) & .9565 & 1 (Ref) & .9290 & 1 (Ref) & .7445 \\
\hline Other & $1.02(0.55$ to 1.88$)$ & & $1.03(0.54$ to 1.96$)$ & & $0.82(0.24$ to 2.75$)$ & \\
\hline \multicolumn{7}{|l|}{ Tumor size, $\mathrm{cm}$} \\
\hline$\leq 2$ & 1 (Ref) & .4112 & 1 (Ref) & .2303 & 1 (Ref) & .7334 \\
\hline$>2$ & $1.20(0.77$ to 1.87$)$ & & 1.33 (0.83 to 2.12$)$ & & 1.15 (0.52 to 2.54$)$ & \\
\hline \multicolumn{7}{|c|}{ No. of positive lymph nodes } \\
\hline 0 & 1 (Ref) & .0089 & 1 (Ref) & $<.001$ & 1 (Ref) & .0028 \\
\hline $1-3$ & 1.89 (1.17 to 3.06$)$ & & 2.32 (1.38 to 3.88$)$ & & 5.00 (1.62 to 15.44$)$ & \\
\hline$\geq 4$ & 2.30 (1.24 to 4.29$)$ & & 3.16 (1.64 to 6.05$)$ & & 8.03 (2.42 to 26.68 ) & \\
\hline
\end{tabular}

Abbreviations: AC, doxorubicin and cyclophosphamide; CMF, cyclophosphamide, methotrexate, and fluorouracil; HR, hazard ratio; Ref, reference. 